\title{
The impact of gastric acid suppression on the developing intestinal microbiome of a child
}

\author{
Spurr Andrew ${ }^{1,2}$, Zhu Wei ${ }^{3}$, Wong Wendy S. W. ${ }^{3}$, Diez Bernadette ${ }^{4}$, Leibowitz lan ${ }^{4}$, Louis- \\ Jacques Otto ${ }^{4}$, Vilboux Thierry ${ }^{5}$, Niederhuber John ${ }^{6}$, Levy Shira $L^{3,7}$ and Hourigan \\ Suchitra $K^{3,4,7}$
}

(1) Georgetown University Systems Medicine, Washington, DC (2) Department of Pediatrics, UPMC Children's Hospital of Pittsburgh, Pittsburgh, PA (3) Inova Translational Medicine Institute, Falls Church, VA (4) Pediatric Specialists of Virginia, Falls Church, VA (5) Persona Biomed Inc., Alexandria, VA (6) Departments of Surgery and Oncology, Johns Hopkins University School of Medicine, Baltimore, MD (7) Inova Children's Hospital, Falls Church, VA 
medRxiv preprint doi: https://doi.org/10.1101/2021.12.21.21268064; this version posted December 23, 2021. The copyright holder for this preprint (which was not certified by peer review) is the author/funder, who has granted medRxiv a license to display the preprint in perpetuity.

It is made available under a CC-BY-NC-ND 4.0 International license.

\section{Abstract}

Gastric acid suppressing medications have been associated with an increased risk of Clostridioides difficile (C. difficile) infection, hypothesized to be due to underlying intestinal microbiome changes. Our goal is to characterize these changes in children as their microbiome is undergoing critical development. Our study included 5 children ( $<3$ years old) who were started on clinically indicated gastric acid suppression and 15 healthy age-matched controls. Stool samples were collected before and after 2 months of treatment. We analyzed the microbiome using $16 \mathrm{~S}$ rRNA sequencing. Quantitative-PCR was used to detect $\mathrm{C}$. difficile toxins. Subjects and controls had similar alpha and beta diversity. We found no significant change in alpha or beta diversity of subjects after treatment. C. difficile toxins were not found and there was no increase in $\mathrm{C}$. difficile carriage after treatment. A significant increase in Lactobacillus was found after treatment, which has been associated with $\mathrm{C}$. difficile in adults. 


\section{Introduction}

The human intestinal microbiome contains at least $10^{14}$ bacteria $(1,2)$, that exist in symbiosis with their host. This community of microorganisms performs vital functions for their host including development and maturation of the immune and metabolic system $(3,4)$. Conversely, imbalance, or dysbiosis, of the microbiome has been associated with a wide range of diseases in humans, from gastrointestinal conditions such as inflammatory bowel disease (IBD) $(5,6)$ and irritable bowel syndrome (7), to metabolic conditions including obesity (8), atopic conditions such as asthma, food allergies and eczema $(9,10)$ and even autism (11).

The microbiome develops rapidly in the first few years of life which shapes future digestive and immune health $(12,13)$. Young children are often prescribed medication to suppress gastric acid, which include proton pump inhibitors (PPIs) and histamine $\mathrm{H} 2$ receptor antagonists (H2RAs), for gastroesophageal reflux and other conditions (14). We are learning more about the potential side effects of these medications including an increased risk of $C$. difficile infection (CDI)(15-18), small bowel bacterial overgrowth (19) and increased risk of allergic disease in children (20). We hypothesize that medications that suppress gastric acid cause a dysbiosis or imbalance in the microbiome of an individual that increases the risk of these side effects. Gastric acid suppression has been associated with microbiome changes to some degree in adult studies (21-24). Freedberg et al. demonstrated a change in taxa previously associated with CDI including an increase in Enterococcaceae and Streptococcaceae and a decrease in Clostridiales (23). Hojo et al. demonstrated a significant increase in Lactobacillus and Streptococcus with PPI treatment (24). However, gut microbial changes with medication to suppress gastric acid has not been well examined in children, who may differ from adults due to a dynamic developing microbiome in the first few years of life compared to a relatively stable microbiome in adults. To the best of our knowledge the only study of the effects of gastric acid suppression on the gut microbiome of pediatric subjects was published by Castellani et al. in 2017 (25). Their study of 12 infants concluded that PPI therapy had only minor effects on the fecal microbiome that were no longer seen after discontinuation of therapy; however there was no control group of healthy untreated infants (25).

Understanding the effect of routinely used gastric acid suppression medications on the developing microbiome of the child will give insight into possible mechanisms for reported side effects and may also provide data to guide appropriate use of these commonly used medications in childhood. This pilot study aimed to examine the longitudinal fecal microbiome of young children prior to starting medication to suppress gastric acid and during therapy compared to healthy age-matched controls not receiving medication. In addition, we aimed to assess the presence of toxigenic $C$. difficile with treatment. 


\section{Methods}

Under the IRB approved protocol (\#16-2215) at the Inova Health System, we enrolled children under the age of 3 years who were prescribed clinically indicated gastric acid suppression medication for gastroesophageal reflux symptoms by their treating physician. Parents provided written consent for participation in the study. Exclusion criteria included: antibiotic use in the preceding three months, use of the same class of medication to suppress gastric acid in the preceding three months, transitioning from a PPI to H2RA in clinic, and a consenting parent younger than 18 years of age. Demographic and clinical data were collected during the clinic visit at which they were first prescribed the medication. Stool from the subject was collected by placement on a fecal occult blood card, a method previously validated, at two time points (26). The first sample was collected prior to initiation of gastric acid suppression medication and second sample was collected two months later. Samples were mailed from home in FDA approved mailers. Fecal occult blood cards were stored at $-80^{\circ} \mathrm{C}$ until analysis.

Age- and gender-matched control subjects who were considered healthy and were not on medication to suppress gastric acid were also included from a longitudinal cohort study within the Inova Health System (IRB protocol \# 15-1804). Stool was collected in the same manner at one time point.

DNA was extracted from the fecal occult blood cards using the Qiagen EZ1 Advanced with the EZ1 Tissue Kit and the Bacterial DNA Extraction protocol card. Samples were cleaned and concentrated using the DNeasy PowerClean Cleanup kit (Qiagen). Sequencing libraries were prepared using a Nextera XT kit (Illumina, San Diego, CA) using a modified Illumina 16S Metagenomics Sequencing Library Preparation protocol for analysis of hypervariable region V4. Each sample was sequenced on the Illumina MiSeq with paired end reads of $301 \mathrm{bp}$. Sequencing of negative controls of lysis buffer and positive controls of Staphylococcus aureus (Strain NCTC 8532, ATCC, VA) and Escherichia coli (Strain NCTC 9001, ATCC, VA) were included.

De-multiplexed sequences were filtered, trimmed, and clustered into operational taxonomic units (OTUs) using the $R$ package DADA2 (version 1.8). While this pipeline is available within the QIIME2 framework, it was used separately to allow for more customization of parameters. The sequence table and OTU table generated by DADA2 were imported into QIIME2 (version 2018.2), where a phylogenetic tree was generated using FastTree and taxonomic identification was performed using the Greengenes 16S rRNA database (version gg 13_8 99\% OTUs). The results were imported into the $R$ package phyloseq (version 1.23.1) to perform alpha diversity (Shannon and Simpson) and beta diversity (weighted unifrac) analyses. Differential abundances were calculated using the $R$ package DESeq2 (version 1.18.1). Graphs and plots were generated using the $R$ package ggplot2 (version 2.2.1). The sequence data are being deposited in NCBI Sequence Read Archive (SRA).

Quantitative-PCR was used to detect $16 \mathrm{~S}$ rRNA, C. difficile toxin A (TcdA), and C. difficile toxin B (TcdB) genes of $C$. difficile as previously described (27). 
medRxiv preprint doi: https://doi.org/10.1101/2021.12.21.21268064; this version posted December 23, 2021. The copyright holder for this preprint (which was not certified by peer review) is the author/funder, who has granted medRxiv a license to display the preprint in perpetuity.

It is made available under a CC-BY-NC-ND 4.0 International license .

\section{Results}

Five children were enrolled in the pilot study, 3 of whom were started on H2RAs and the remaining 2 on PPIs (Table 1). Two stool samples from each subject ("Before" treatment and "After" treatment) were included in the analysis. Fifteen age-matched controls were also included who were not on medication to suppress gastric acid (Table 2).

Table 1: Subject demographic and clinical information. Subject 4 was treated with antibiotics for 2 days while enrolled in the study. Age quartiles based on age range of 1 to 33 months.

\begin{tabular}{|r|l|r|l|l|l|}
\hline \multicolumn{1}{|c|}{ Subject ID } & Gender & Age at first sample & Medication Type & Antibiotics & Diet \\
\hline 1 & $\mathrm{~F}$ & $4^{\text {th }}$ quartile & PPI & None & Cow's milk, almond milk, solid food \\
\hline 4 & $\mathrm{M}$ & $1^{\text {st }}$ quartile & H2RA & 2 days & Cow's milk formula \\
\hline 8 & $\mathrm{M}$ & $2^{\text {nd }}$ quartile & H2RA & None & Cow's milk formula \\
\hline 10 & $\mathrm{~F}$ & $3^{\text {rd }}$ quartile & H2RA & None & Cow's milk, solid food \\
\hline 12 & $\mathrm{M}$ & $2^{\text {nd }}$ quartile & PPI & None & Cow's milk formula \\
\hline
\end{tabular}

Table 2: Demographics of controls with their corresponding subjects. Age quartiles based on age range of 1 to 33 months.

\begin{tabular}{|c|c|c|c|c|}
\hline Subject ID & Subject Age & Control ID & Gender & Age (months) \\
\hline 1 & $4^{\text {th }}$ quartile & $\begin{array}{l}\text { 001B_1 } \\
\text { 001B_2 } \\
\text { 001B_3 }\end{array}$ & $\begin{array}{l}\text { FEMALE } \\
\text { FEMALE } \\
\text { FEMALE }\end{array}$ & $\begin{array}{l}4^{\text {th }} \text { quartile } \\
4^{\text {th }} \text { quartile } \\
4^{\text {th }} \text { quartile }\end{array}$ \\
\hline 4 & $1^{\text {st }}$ quartile & $\begin{array}{l}004 B \_1 \\
004 B \_2 \\
004 B \_3\end{array}$ & $\begin{array}{l}\text { MALE } \\
\text { MALE } \\
\text { MALE }\end{array}$ & $\begin{array}{l}3^{\text {rd }} \text { quartile } \\
3^{\text {rd }} \text { quartile } \\
3^{\text {rd }} \text { quartile }\end{array}$ \\
\hline 8 & $2^{\text {nd }}$ quartile & $\begin{array}{l}\text { 008B_1 } \\
\text { 008B_2 } \\
\text { 008B_3 }\end{array}$ & $\begin{array}{l}\text { MALE } \\
\text { MALE } \\
\text { MALE }\end{array}$ & $\begin{array}{l}3^{\text {rd }} \text { quartile } \\
3^{\text {rd }} \text { quartile } \\
3^{\text {rd }} \text { quartile }\end{array}$ \\
\hline 10 & $3^{\text {rd }}$ quartile & $\begin{array}{l}\text { 010B_1 } \\
\text { 010B_2 } \\
\text { 010B_3 }\end{array}$ & $\begin{array}{l}\text { FEMALE } \\
\text { FEMALE } \\
\text { FEMALE }\end{array}$ & $\begin{array}{l}3^{\text {rd }} \text { quartile } \\
3^{\text {rd }} \text { quartile } \\
4^{\text {th }} \text { quartile }\end{array}$ \\
\hline 12 & $2^{\text {nd }}$ quartile & $\begin{array}{l}\text { 012B_1 } \\
\text { 012B_2 } \\
\text { 012B_3 }\end{array}$ & $\begin{array}{l}\text { MALE } \\
\text { MALE } \\
\text { MALE }\end{array}$ & $\begin{array}{l}3^{\text {rd }} \text { quartile } \\
3^{\text {rd }} \text { quartile } \\
3^{\text {rd }} \text { quartile }\end{array}$ \\
\hline
\end{tabular}




\section{Alpha and Beta Diversity}

Alpha diversity was calculated using the Shannon Index. There was no significant change in alpha-diversity before and after gastric acid suppression ( $p=0.51$, Figure 1). Beta-diversity was determined using PCoA unifrac (weighted). Samples from the same individual before and after treatment clustered well together. Samples also clustered well by gender. Samples did not cluster by type of gastric acid suppression medication, nor by time point (before vs. after taking medication) (Figure 1).

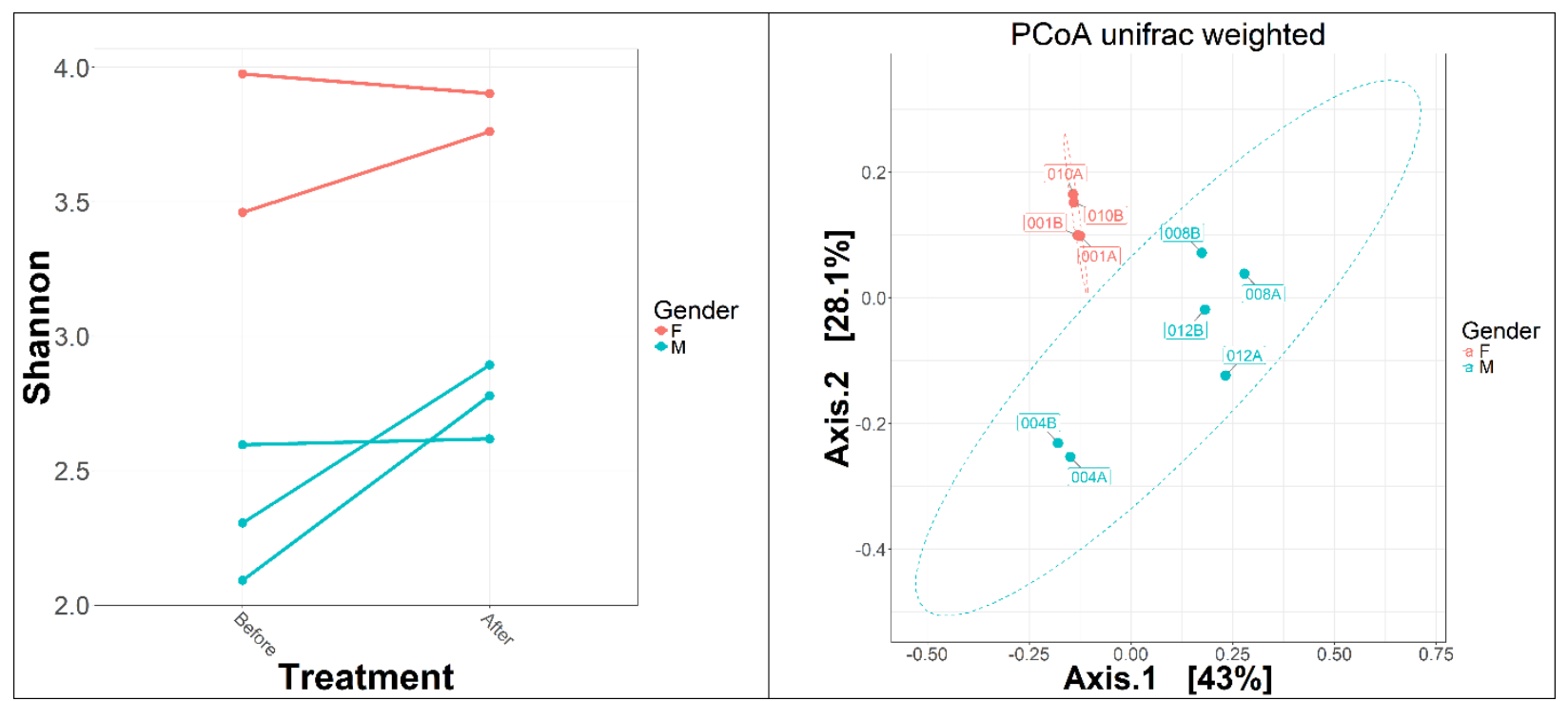

Figure 1: Shannon diversity (left) and beta diversity as measured by weighted unifrac (right). There was no significant change in Shannon diversity after gastric acid suppression. Samples clustered well by gender, however they did not cluster by type of medication, nor by time point.

\section{Relative Abundance of Taxa}

Bacterial abundance before and after gastric acid suppression were calculated for each taxon (Table 3). Of note, the phylum Proteobacteria and the genus Neisseria significantly decreased after medication ( $p=$ $0.018, p=0.028$, respectively) and Lactobacillus significantly increased after medication $(p=0.002)$. Females had a significant decrease in Enterococcus $(p=0.024)$. Males had a significant decrease in Enterobacter $(p=0.038)$. Subjects taking H2RAs had a significant decrease in both Haemophilus and Neisseria. While only a select few taxa were significantly different when pooling different subjects together, there were more dramatic changes in taxa on an individual level after medication (Figure 2). 
medRxiv preprint doi: https://doi.org/10.1101/2021.12.21.21268064; this version posted December 23, 2021. The copyright holder for this preprint (which was not certified by peer review) is the author/funder, who has granted medRxiv a license to display the preprint in perpetuity.

It is made available under a CC-BY-NC-ND 4.0 International license .

Table 3: Significant changes in differential abundances from before and after medication use. Any taxon with a p-value had a significant change in abundance after medication. A negative log2 fold change indicates a decrease in abundance after medication and a positive $\log 2$ fold change indicates an increase in abundance after medication.

\begin{tabular}{|c|c|c|c|c|c|c|c|c|}
\hline Group & Phylum & Class & Order & Family & Genus & baseMean & log2FoldChange & pvalue \\
\hline \multirow{9}{*}{ ALL } & Proteobacteria & & & & & 13554.61 & -3.01 & 0.018 \\
\hline & & Gammaproteobacteria & Pasteurellales & & & 181.74 & -3.84 & 0.041 \\
\hline & & Betaproteobacteria & Neisseriales & & & 4.50 & -5.34 & 0.034 \\
\hline & & & & Neisseriaceae & & 3.99 & -5.16 & 0.050 \\
\hline & & & & & Neisseria & 6.72 & -6.11 & 0.028 \\
\hline & Firmicutes & & & & & & & \\
\hline & & Erysipelotrichi & Erysipelotrichales & Erysipelotrichaceae & Coprobacillus & 62.60 & 7.94 & 0.004 \\
\hline & & Bacilli & Lactobacillales & Lactobacillaceae & Lactobacillus & 33.77 & 9.34 & 0.002 \\
\hline & & Clostridia & Clostridiales & Lachnospiraceae & Dorea & 1002.90 & 4.14 & 0.024 \\
\hline \multirow{2}{*}{ MALE } & Proteobacteria & Gammaproteobacteria & Enterobacteriales & Enterobacteriaceae & Enterobacter & 31.19 & -6.00 & 0.038 \\
\hline & & Clostridia & Clostridiales & Lachnospiraceae & Dorea & 1456.40 & 7.14 & 0.006 \\
\hline \multirow{7}{*}{ FEMALE } & Firmicutes & & & & & & & \\
\hline & & Bacilli & Lactobacillales & Enterococcaceae & & 119.30 & -4.59 & 0.031 \\
\hline & & & & & Enterococcus & 161.73 & -5.16 & 0.024 \\
\hline & & Clostridia & Clostridiales & Veillonellaceae & Megasphaera & 620.33 & 7.29 & 0.040 \\
\hline & Actinobacteria & & & & & & & \\
\hline & & Actinobacteria & Actinomycetales & Corynebacteriaceae & & 33.22 & 8.67 & 0.002 \\
\hline & & & & & Corynebacterium & 34.81 & 8.64 & 0.005 \\
\hline \multirow{11}{*}{ H2RA } & Firmicutes & & & & & & & \\
\hline & & Erysipelotrichi & & & & 2304.17 & 6.46 & 0.039 \\
\hline & & & Erysipelotrichales & & & 2272.70 & 6.80 & 0.016 \\
\hline & & & & Erysipelotrichaceae & Coprobacillus & 62.06 & 6.88 & 0.039 \\
\hline & & Bacilli & Lactobacillales & Lactobacillaceae & Lactobacillus & 41.83 & 8.69 & 0.020 \\
\hline & & Clostridia & Clostridiales & Ruminococcaceae & Ruminococcus & 233.60 & 7.82 & 0.020 \\
\hline & Proteobacteria & & & & & & & \\
\hline & & Gammaproteobacteria & Pasteurellales & Pasteurellaceae & & 48.28 & -5.11 & 0.043 \\
\hline & & & & & Haemophilus & 75.53 & -6.04 & 0.026 \\
\hline & & Betaproteobacteria & Neisseriales & Neisseriaceae & & 7.67 & -6.24 & 0.035 \\
\hline & & & & & Neisseria & 11.15 & -7.16 & 0.021 \\
\hline
\end{tabular}




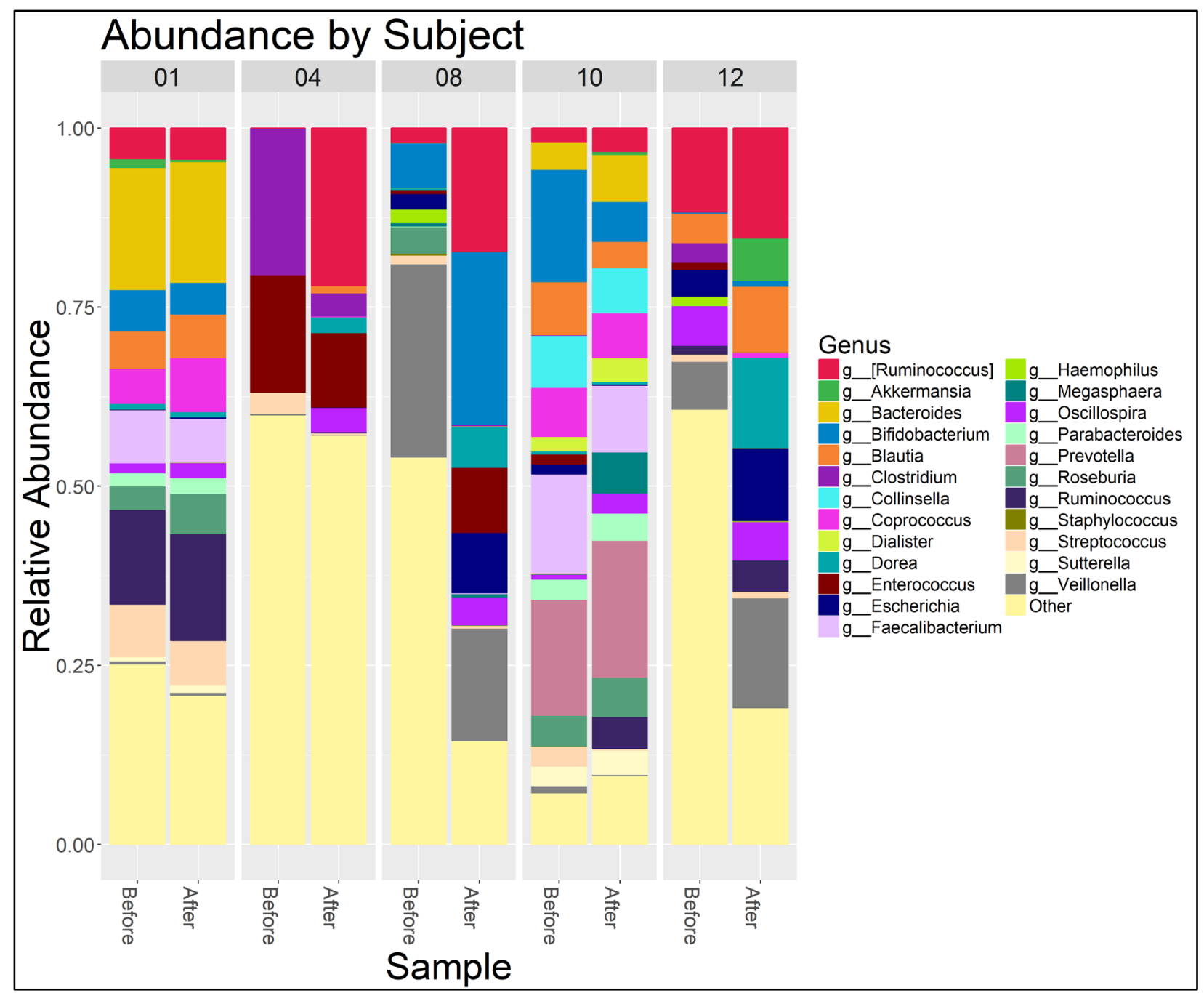

Figure 2: Relative abundance of the most abundant genera in each sample.

\section{C. difficile toxin}

C. difficile toxin $A(T c d A)$ and $C$. difficile toxin $B(T c d B)$ were not found in any of the subjects. Nontoxigenic

C. difficile was present only in one subject, both before and after PPI treatment.

\section{Control Comparisons}

In order to account for age- and gender-related differences in microbial composition and diversity, we compared our subjects to three controls each of the same gender and similar age (Table 2). The controls had not been treated with antibiotics or medication to suppress gastric acid. They did not have clinically diagnosed gastroesophageal reflux disease.

\section{Alpha diversity}

The Shannon diversity, which takes into account not only the presence of certain OTUs, but the abundance as well, of the age- and gender-matched controls is similar to the diversity of the experimental samples (Figure 3, Table 4). The Shannon diversity of subjects and controls generally increases with age (Figure 4). 


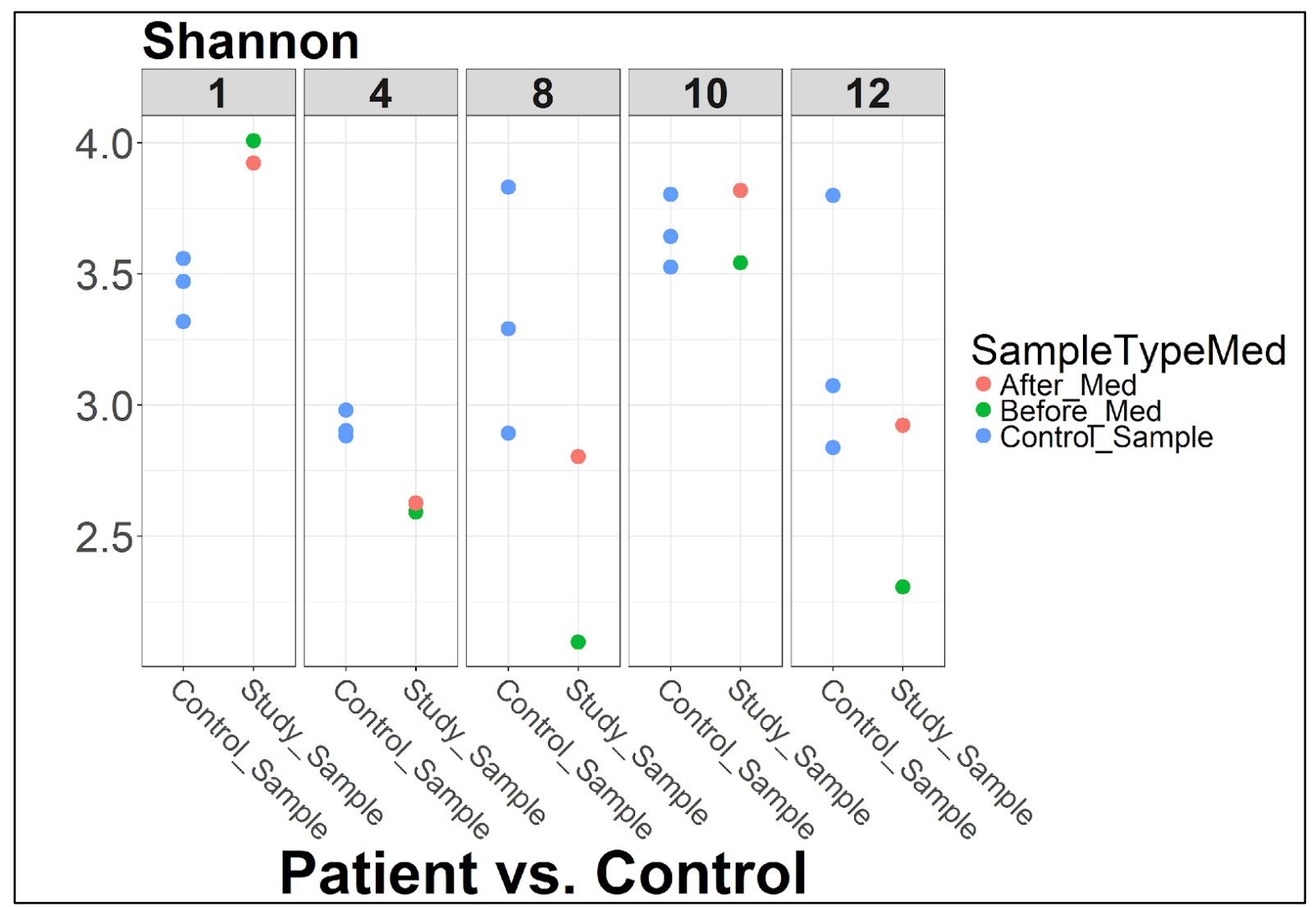

Figure 3: Comparison of alpha diversity to age- and gender-matched controls.

Table 4: P-values for mean Shannon Diversity of subjects vs. their age-matched controls.

\begin{tabular}{|l|r|r|r|l|l|}
\hline Subject & $\begin{array}{c}\text { Mean Shannon } \\
\text { Control Sample }\end{array}$ & $\begin{array}{c}\text { Mean Shannon } \\
\text { Study Sample }\end{array}$ & p value & \multicolumn{1}{|c|}{ Gender } & \multicolumn{1}{|c|}{ Med } \\
\hline Subject 1 & 3.45 & 3.97 & 0.009 & F & PPI \\
\hline Subject 4 & 2.92 & 2.61 & 0.003 & M & H2RA \\
\hline Subject 8 & 3.34 & 2.45 & 0.176 & M & H2RA \\
\hline Subject 10 & 3.66 & 3.68 & 0.903 & F & H2RA \\
\hline Subject 12 & 3.24 & 2.62 & 0.252 & M & PPI \\
\hline
\end{tabular}




\section{Shannon Diversity vs. Age}

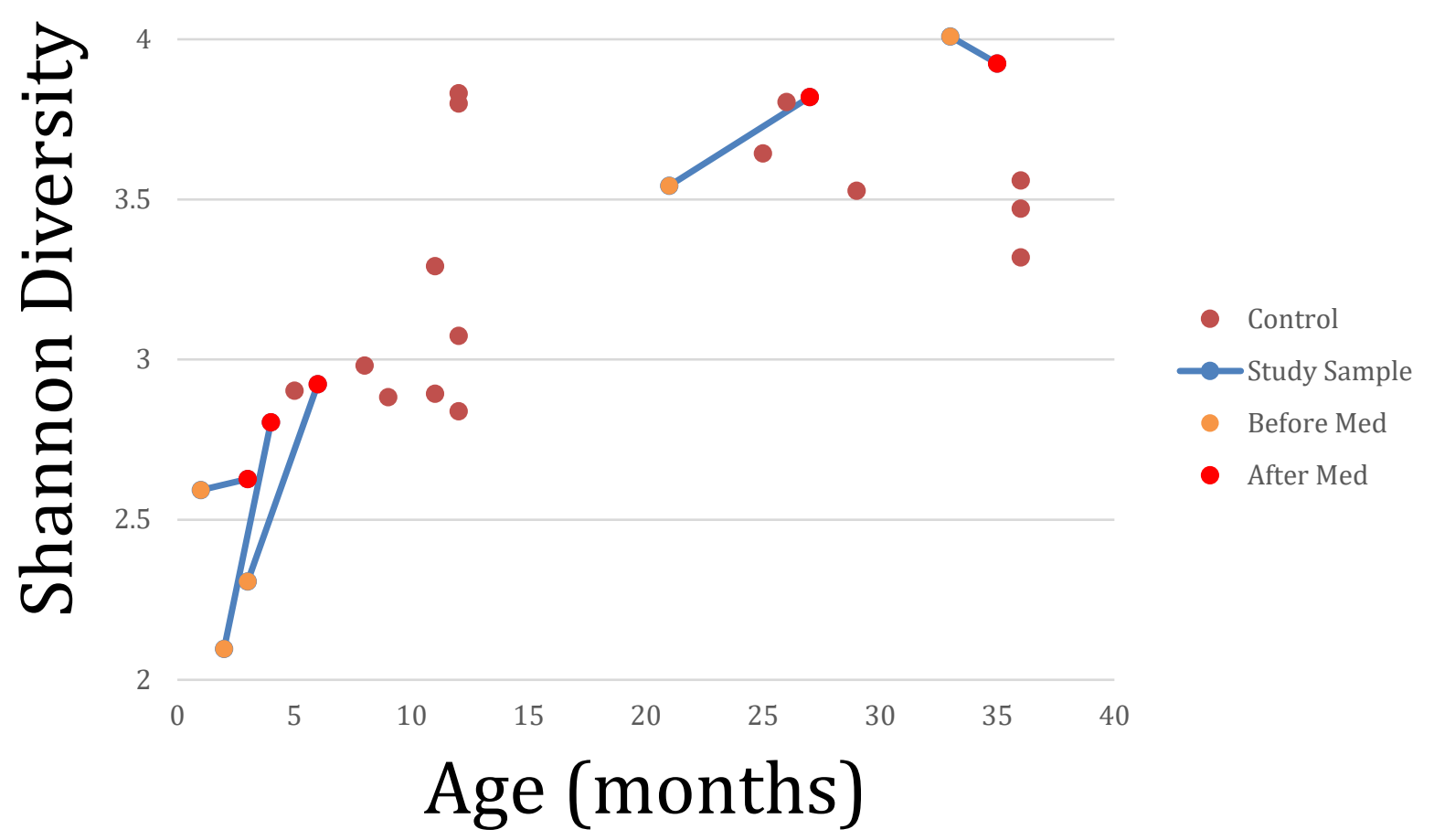

Figure 4: Shannon Diversity of controls and subjects vs. age. The blue lines connect the same subject before and after medication.

\section{Beta diversity}

We performed PCoA Unifrac weighted analysis on the entirety of the samples (Figure 5). This included two samples from each of the five subjects and three controls (one sample each) for each subject, for a total of 25 samples. Overall, this shows clustering by age. The cluster of samples in the lower left corner represent ages 8 months and greater, whereas the samples in the periphery represent ages 7 months or less $(p=0.001)$. 


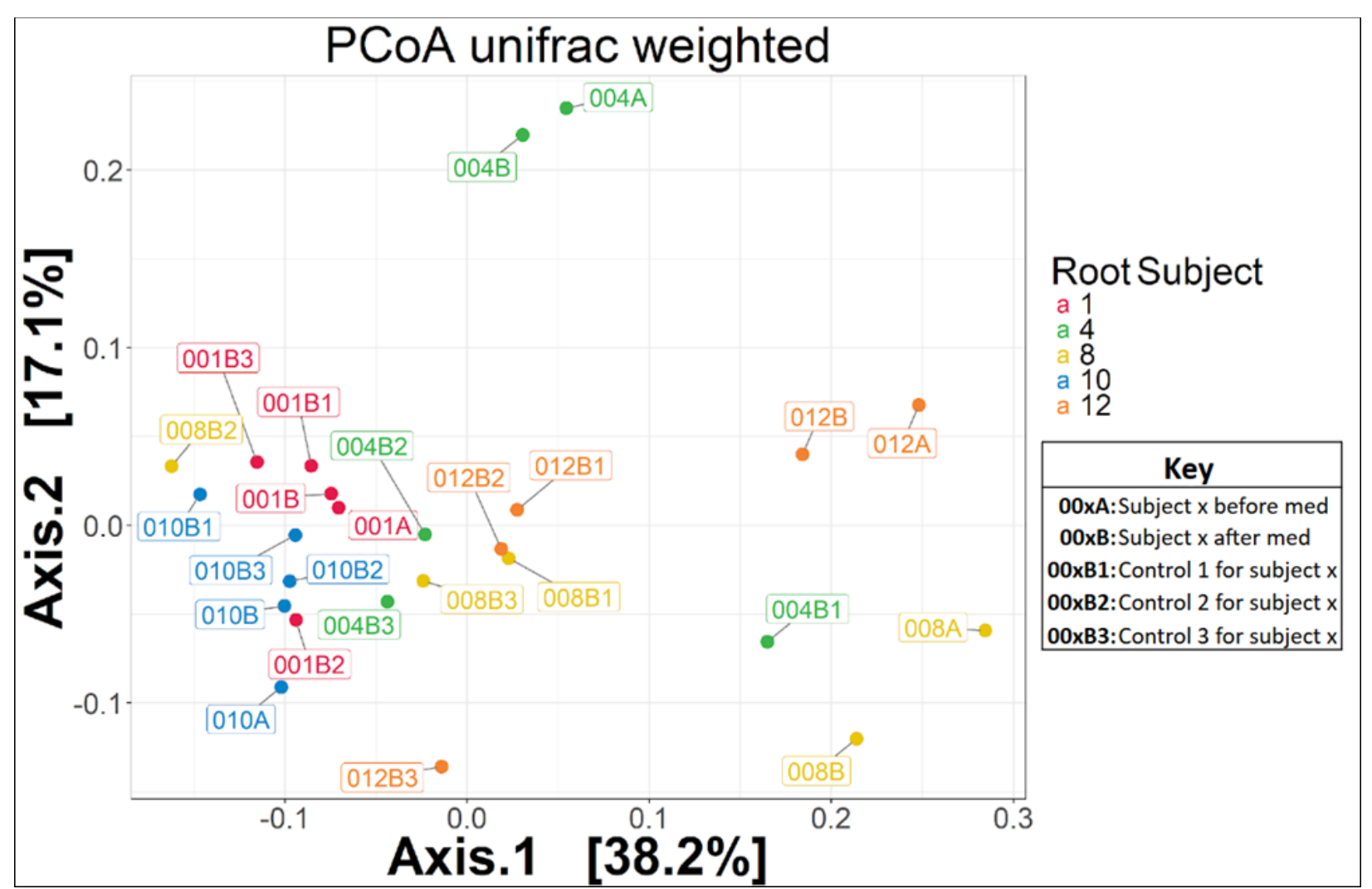

Figure 5: Ordination of experimental and control samples. The data points are color-coded by subject. For example, 001A represents subject 1 before medication. 001B represents subject 1 after medication. 001B1, 001B2, 001B3 represent the three controls for subject 1.

\section{Relative abundance of taxa}

As part of the control analysis, we compared bacterial abundance of the controls to the post-treatment subjects (Table 5). Among others, we found a lower abundance in the order Pasteurellales $(p=0.008)$, the family Lachnospiraceae $(p=0.046)$, and in the genus Haemophilus $(p=0.001)$ in post-treatment group. 
medRxiv preprint doi: https://doi.org/10.1101/2021.12.21.21268064; this version posted December 23, 2021. The copyright holder for this preprint (which was not certified by peer review) is the author/funder, who has granted medRxiv a license to display the preprint in perpetuity.

It is made available under a CC-BY-NC-ND 4.0 International license .

Table 5: Significant changes in differential abundances between controls and subjects post-treatment. Any taxon with a p-value represents a significant difference in abundance. A negative log2 fold change indicates a lower abundance in subjects post-treatment and a positive log2 fold change indicates a higher abundance in subjects post-treatment.

\begin{tabular}{|c|c|c|c|c|c|c|c|}
\hline Phylum & Class & Order & Family & Genus & baseMean & log2FoldChange & pvalue \\
\hline \multicolumn{8}{|l|}{ Actinobacteria } \\
\hline & Actinobacteria & Actinomycetales & & & 40.52 & 1.98 & 0.004 \\
\hline & & & Actinomycetaceae & & 21.00 & 1.36 & 0.046 \\
\hline & Coriobacteriia & Coriobacteriales & Coriobacteriaceae & Collinsella & 205.79 & 6.74 & 0.002 \\
\hline \multirow[t]{4}{*}{ Bacteroidetes } & Bacteroidia & Bacteroidales & & & & & \\
\hline & & & Bacteroidaceae & & 13631.74 & -2.37 & 0.047 \\
\hline & & & Prevotellaceae & Prevotella & 627.16 & 7.89 & 0.000 \\
\hline & & & Bacteroidaceae & Bacteroides & 13272.34 & -2.36 & 0.049 \\
\hline \multirow[t]{16}{*}{ Firmicutes } & Bacilli & & & & & & \\
\hline & & Lactobacillales & Carnobacteriaceae & & 8.15 & -2.40 & 0.031 \\
\hline & & Bacillales & Paenibacillaceae & & 15.42 & 7.60 & 0.024 \\
\hline & & & & Paenibacillus & 19.80 & 7.67 & 0.023 \\
\hline & Clostridia & Clostridiales & & & & & \\
\hline & & & Peptostreptococcaceae & & 670.37 & 1.46 & 0.009 \\
\hline & & & Eubacteriaceae & Garciella & 4.07 & 22.21 & 0.000 \\
\hline & & & Veillonellaceae & & & & \\
\hline & & & & Phascolarctobacterium & 60.30 & 7.73 & 0.011 \\
\hline & & & & Megamonas & 16.90 & -21.52 & 0.000 \\
\hline & & & Ruminococcaceae & & & & \\
\hline & & & & Faecalibacterium & 9198.63 & -2.49 & 0.023 \\
\hline & & & & Oscillospira & 1082.53 & 1.21 & 0.025 \\
\hline & & & Lachnospiraceae & & 29147.03 & -0.71 & 0.046 \\
\hline & & & & Blautia & 5943.13 & -1.67 & 0.030 \\
\hline & & & & Lachnospira & 2142.40 & -2.98 & 0.023 \\
\hline \multirow[t]{5}{*}{ Fusobacteria } & & & & & 61.30 & 6.08 & 0.001 \\
\hline & Fusobacteriia & & & & 59.82 & 6.00 & 0.000 \\
\hline & & Fusobacteriales & & & 67.27 & 6.04 & 0.001 \\
\hline & & & Fusobacteriaceae & & 67.00 & 6.17 & 0.001 \\
\hline & & & & Fusobacterium & 63.86 & 5.88 & 0.002 \\
\hline \multirow[t]{9}{*}{ Proteobacteria } & & & & & 2735.97 & 1.29 & 0.026 \\
\hline & Alphaproteobacteria & & & & 36.64 & -4.68 & 0.012 \\
\hline & & RF32 & & & 38.32 & -22.64 & 0.000 \\
\hline & Epsilonproteobacteria & & & & 25.74 & 6.31 & 0.010 \\
\hline & & Campylobacterales & & & 21.00 & 5.58 & 0.027 \\
\hline & Gammaproteobacteria & Pasteurellales & & & 165.43 & -2.55 & 0.008 \\
\hline & & & Pasteurellaceae & & 184.22 & -2.72 & 0.006 \\
\hline & & & & Haemophilus & 229.88 & -3.62 & 0.001 \\
\hline & Gammaproteobacteria & Enterobacteriales & Enterobacteriaceae & Proteus & 37.37 & 7.76 & 0.016 \\
\hline
\end{tabular}




\section{Discussion}

To the best of our knowledge, we are the first to study the effects of gastric acid suppression on the microbiome of children with the use of age-matched controls, as well as to use qPCR to detect toxigenic and nontoxigenic $C$. difficile. We found a significant increase of Lactobacillus, however, we did not detect toxigenic $C$. difficile in our samples. In our control analysis, we found that both alpha and beta diversity were more strongly correlated with age than other factors (presence of GERD, treatment with gastric acid suppression, type of medication).

In 2015 there were two large studies comparing the microbiomes of adults who use PPIs to those who do not. Jackson et al. did not find significant changes in alpha diversity when correcting for covariates associated with PPI use such as age, BMI, and antibiotic use (21). Imhann et al. did find a significant decrease in alpha diversity with PPI use (22), however did not mention any correction of covariates. There have since been two smaller prospective studies comparing the gut microbiomes of adults before and after PPI use $(23,24)$. While Freedberg et al. showed no difference in alpha diversity after PPI use, there were changes in taxa associated with CDI (increased Enterococcaceae and Streptococcaceae, decreased Clostridiales) (23). Hojo et al. used quantitative RT-PCR for 22 different taxa. They found significant increases in Lactobacillus and Enterobacteriaceae (shown to be associated with CDI in adults (28)), as well as Streptococcus and Staphylococcus. Of the taxa mentioned in these two studies, our study only replicated the significant increase in Lactobacillus.

The only other study investigating the effects of gastric acid suppression on children was in 2017 by Castellani et al. They compared the microbiome of infants at three time points: before starting a PPI, 4 weeks into PPI treatment, and 4 weeks after discontinuation of PPI treatment. When comparing baseline microbiome to 4 weeks of PPI treatment, this study showed no significant change in alpha or beta diversity. They found a significant change in alpha diversity when comparing their post-PPI group to both the pre-PPI and during-PPI group (25). Commentary on this study by Drall et al. in 2018 suggests that this initial lack of change in diversity may actually represent a deviation from the normal increase in diversity that would occur during microbiome development at this age (29). We also did not observe a significant change in alpha diversity when pooling our subjects together, however, four out of five of our subjects showed an increase in alpha diversity after two months of treatment, following a similar trajectory to their age-matched controls (Figure 4).

Castellani et al. compared microbial composition before treatment to 4 weeks into treatment and found a significant decrease in Lactobacillus and Stenotrophomonas and a significant increase of Haemophilus. In contrast, we showed an increase in Lactobacillus, as previously shown in adult studies (24), which has also been shown to be positively correlated with CDI in adults (28) .

Given our use of age-matched controls, we were able to perform novel analyses. We found that the betadiversity of our older subjects (> 7 months old) was similar to their age-matched controls (Figure 5). When comparing the taxa of our controls to the post-treatment subjects, we found significantly lower abundances of Pasteurellales and Haemophilus in the post-treatment group. This was also found when 
comparing our subjects pre-treatment and post-treatment. This finding supports the notion that this change in microbial abundance is associated more with gastric acid suppression rather than natural progression of the microbiome. We also found a significantly lower abundance of Lachnospiraceae in subjects-post-treatment, which has been shown to be lower in adults with CDI (28). We also performed $C$. difficile toxin PCR to detect toxigenic $C$. difficile. Nontoxigenic $C$. difficile was present only in one subject both before and after PPI treatment. Surprisingly, no toxigenic $C$. difficile was found even though asymptomatic carriage has a high prevalence at this age (30).

\section{Limitations}

A major limitation is our sample size. The small sample size is due to a decrease in the use of PPIs and H2RAs just as the study was started. With a larger sample of both subjects and controls, we would be able to better characterize normal microbiome development and potential deviations in this development in our experimental group. It is possible that, like Castellani's study, our lack of change in alpha diversity with PPI use actually represents a deviation from the normal increase in diversity you would see in this age group. In addition, a larger sample size would allow us to better assess whether there are differential microbiome changes between different classes of medication (H2RA vs. PPI).

\section{Conclusion}

The goal of this study was to further characterize the effect of gastric acid suppression medications on the developing microbiome of children. This is a difficult task given the fact that there is variability in the development of the microbiome in the first few years of life, with effects from both intrinsic and extrinsic factors, and no universally agreed-upon "normal" development. With this in mind, we compared our subjects to healthy age-matched controls and found that both the alpha and beta diversities in our subjects resembled the controls, even after use of gastric acid suppression. While we did not detect toxigenic $C$. difficile in our samples, we did find a significant increase of Lactobacillus, which has been previously associated with CDI in adults. These pilot results warrant further exploration in a larger cohort. 
medRxiv preprint doi: https://doi.org/10.1101/2021.12.21.21268064; this version posted December 23, 2021. The copyright holder for this preprint (which was not certified by peer review) is the author/funder, who has granted medRxiv a license to display the preprint in perpetuity.

It is made available under a CC-BY-NC-ND 4.0 International license .

\section{Funding}

The author(s) disclosed receipt of the following financial support for the research, authorship, and/or publication of this article: This work was supported by the National Institute of Child Health and Human Development under Award Number [grant number K23HD099240]; and the Inova Research Seed Grant.

\section{Declaration of Conflicting Interests:}

The Author(s) declare(s) that there is no conflict of interest 


\section{References}

1. Gill SR, Pop M, Deboy RT, et al. Metagenomic analysis of the human distal gut microbiome. Science. 2006 Jun 2;312(5778):1355-9.

2. Qin J, Li R, Raes J, et al. A human gut microbial gene catalogue established by metagenomic sequencing. Nature. 2010 Mar 4;464(7285):59-65.

3. Lee YK, Mazmanian SK. Has the microbiota played a critical role in the evolution of the adaptive immune system? Science. 2010 Dec 24;330(6012):1768-73.

4. Martin AM, Sun EW, Rogers GB, Keating DJ. The Influence of the Gut Microbiome on Host Metabolism Through the Regulation of Gut Hormone Release. Front Physiol. 2019 Apr 16;10.

5. Manichanh C, Borruel N, Casellas F, Guarner F. The gut microbiota in IBD. Nat Rev Gastroenterol Hepatol. 2012 Oct;9(10):599-608.

6. Frank DN, St Amand AL, Feldman RA, Boedeker EC, Harpaz N, Pace NR. Molecularphylogenetic characterization of microbial community imbalances in human inflammatory bowel diseases. Proc Natl Acad Sci USA. 2007 Aug 21;104(34):13780-5.

7. Collins SM. A role for the gut microbiota in IBS. Nat Rev Gastroenterol Hepatol. 2014 Aug;11(8):497-505.

8. Tilg H, Kaser A. Gut microbiome, obesity, and metabolic dysfunction. J Clin Invest. 2011 Jun;121(6):2126-32.

9. Fujimura KE, Demoor T, Rauch M, et al. House dust exposure mediates gut microbiome Lactobacillus enrichment and airway immune defense against allergens and virus infection. Proc Natl Acad Sci USA. 2014 Jan 14;111(2):805-10.

10. West CE, Rydén P, Lundin D, Engstrand L, Tulic MK, Prescott SL. Gut microbiome and innate immune response patterns in IgE-associated eczema. Clin Exp Allergy. 2015 Sep;45(9):1419-29.

11. Hsiao EY, McBride SW, Hsien S, et al. Microbiota modulate behavioral and physiological abnormalities associated with neurodevelopmental disorders. Cell. 2013 Dec 19;155(7):1451-63.

12. Putignani L, Del Chierico F, Petrucca A, Vernocchi P, Dallapiccola B. The human gut microbiota: a dynamic interplay with the host from birth to senescence settled during childhood. Pediatr Res. 2014 Jul;76(1):2-10.

13. Yatsunenko T, Rey FE, Manary MJ, et al. Human gut microbiome viewed across age and geography. Nature. 2012 May 9;486(7402):222-7.

14. Tighe M, Afzal NA, Bevan A, Hayen A, Munro A, Beattie RM. Pharmacological treatment of children with gastro-oesophageal reflux. Cochrane Database Syst Rev. 2014 Nov 24;(11):CD008550.

15. Jimenez J, Drees M, Loveridge-Lenza B, Eppes S, delRosario F. Exposure to Gastric AcidSuppression Therapy Is Associated With Health Care- and Community-Associated 
Clostridium difficile Infection in Children. J Pediatr Gastroenterol Nutr. 2015 Aug;61(2):208-11.

16. McDonald EG, Milligan J, Frenette C, Lee TC. Continuous Proton Pump Inhibitor Therapy and the Associated Risk of Recurrent Clostridium difficile Infection. JAMA Intern Med. 2015 May;175(5):784-91.

17. Freedberg DE, Lamousé-Smith ES, Lightdale JR, Jin Z, Yang Y-X, Abrams JA. Use of Acid Suppression Medication is Associated With Risk for C. difficile Infection in Infants and Children: A Population-based Study. Clin Infect Dis. 2015 Sep 15;61(6):912-7.

18. Oshima T, Wu L, Li M, Fukui H, Watari J, Miwa H. Magnitude and direction of the association between Clostridium difficile infection and proton pump inhibitors in adults and pediatric patients: a systematic review and meta-analysis. J Gastroenetrol. 2018 Jan;53(1):84-94.

19. Sieczkowska A, Landowski P, Zagozdzon P, Kaminska B, Lifschitz C. Small Bowel Bacterial Overgrowth Associated with Persistence of Abdominal Symptoms in Children Treated with a Proton Pump Inhibitor. J Pediatr. 2015 May;166(5):1310-1312.e1.

20. Mitre E, Susi A, Kropp LE, Schwartz DJ, Gorman GH, Nylund CM. Association Between Use of Acid-Suppressive Medications and Antibiotics During Infancy and Allergic Diseases in Early Childhood. JAMA Pediatr. 2018 Jun;172(6).

21. Jackson MA, Goodrich JK, Maxan M-E, et al. Proton pump inhibitors alter the composition of the gut microbiota. Gut. 2016 May;65(5):749-56.

22. Imhann F, Bonder MJ, Vila AV, et al. Proton pump inhibitors affect the gut microbiome. Gut. 2016 May 1;65(5):740-8.

23. Freedberg DE, Toussaint NC, Chen SP, et al. Proton Pump Inhibitors Alter Specific Taxa in the Human Gastrointestinal Microbiome: A Crossover Trial. Gastroenterology. 2015 Oct;149(4):883-885.e9.

24. Hojo M, Asahara T, Nagahara A, et al. Gut Microbiota Composition Before and After Use of Proton Pump Inhibitors. Dig Dis Sci. 2018;63(11):2940-9.

25. Castellani C, Singer G, Kashofer K, et al. The Influence of Proton Pump Inhibitors on the Fecal Microbiome of Infants with Gastroesophageal Reflux-A Prospective Longitudinal Interventional Study. Front Cell Infect Microbiol. 2017 Oct 11;7:444.

26. Wong WSW, Clemency N, Klein E, et al. Collection of non-meconium stool on fecal occult blood cards is an effective method for fecal microbiota studies in infants. Microbiome. 2017 05;5(1):114.

27. Kubota H, Sakai T, Gawad A, et al. Development of TaqMan-based quantitative PCR for sensitive and selective detection of toxigenic Clostridium difficile in human stools. PLoS ONE. 2014;9(10):e111684.

28. Seekatz AM, Young VB. Clostridium difficile and the microbiota. J Clin Invest. 2014 Oct $1 ; 124(10): 4182-9$. 
medRxiv preprint doi: https://doi.org/10.1101/2021.12.21.21268064; this version posted December 23, 2021. The copyright holder for this preprint (which was not certified by peer review) is the author/funder, who has granted medRxiv a license to display the preprint in perpetuity.

It is made available under a CC-BY-NC-ND 4.0 International license .

29. Drall K, Tun H, Kozyrskyj A. Commentary: The Influence of Proton Pump Inhibitors on the Fecal Microbiome of Infants with Gastroesophageal Reflux-A Prospective Longitudinal Interventional Study. Front Cell Infect Microbiol. 2018 Dec;8:430.

30. Jangi S, Lamont JT. Asymptomatic Colonization by Clostridium difficile in Infants: Implications for Disease in Later Life. Journal of Pediatric Gastroenterology and Nutrition. $2010 \mathrm{Jul} ; 51(1): 2-7$. 